\title{
Pectic arabinan side chains are essential for pollen cell wall integrity during pollen development
}

\author{
Katarina Cankar ${ }^{1, \dagger}$, , Anne Kortstee ${ }^{1, \$}$, Marcel A.J. Toonen ${ }^{1}$, Mieke Wolters-Arts ${ }^{2}$, Rudolf Houbein ${ }^{1}$, Celestina \\ Mariani ${ }^{2}$, Peter Ulvskov ${ }^{3}$, Bodil Jorgensen ${ }^{3}$, Henk A. Schols ${ }^{4}$, Richard G.F. Visser ${ }^{1}$ and Luisa M. Trindade ${ }^{1, *}$ \\ ${ }^{1}$ Wageningen UR Plant Breeding, Wageningen University and Research Centre, Wageningen, the Netherlands \\ ${ }^{2}$ Department of Molecular Plant Physiology, Institute of Water and Wetlands Research, Radboud University, Nijmegen, the Netherlands \\ ${ }^{3}$ Department of Plant Biology \& Biotechnology, University of Copenhagen, Frederiksberg, Denmark \\ ${ }^{4}$ Laboratory of Food Chemistry, Wageningen University, Wageningen, the Netherlands
}

Received 12 September 2013;

revised 10 November 2013;

accepted 13 November 2013.

*Correspondence (Tel +31317482127;

fax +31 317 483457;

email luisa.trindade@wur.nl)

†Present address: Department of Plant

Physiology, Wageningen University,

Wageningen, the Netherlands.

These authors contributed equally to the paper.

This project was supported by funds of the European Community contact FP6-

NMP-517036 'Pecticoat', by the Villum Kann Rasmussen Foundation and by the

Technology Foundation STW project 10625

Keywords: pectin, arabinan, cell wall modification, pollen sterility, potato,

Solanum tuberosum.

\begin{abstract}
Summary
Pectin is a complex polysaccharide and an integral part of the primary plant cell wall and middle lamella, contributing to cell wall mechanical strength and cell adhesion. To understand the structure-function relationships of pectin in the cell wall, a set of transgenic potato lines with altered pectin composition was analysed. The expression of genes encoding enzymes involved in pectin acetylation, degradation of the rhamnogalacturonan backbone and type and length of neutral side chains, arabinan and galactan in particular, has been altered. Upon crossing of different transgenic lines, some transgenes were not transmitted to the next generation when these lines were used as a pollen donor, suggesting male sterility. Viability of mature pollen was severely decreased in potato lines with reduced pectic arabinan, but not in lines with altered galactan side chains. Anthers and pollen of different developmental stages were microscopically examined to study the phenotype in more detail. Scanning electron microscopy of flowers showed collapsed pollen grains in mature anthers and in earlier stages cytoplasmic protrusions at the site of the of kin pore, eventually leading to bursting of the pollen grain and leaking of the cytoplasm. This phenomenon is only observed after the microspores are released and the tapetum starts to degenerate. Timing of the phenotype indicates a role for pectic arabinan side chains during remodelling of the cell wall when the pollen grain is maturing and dehydrating.
\end{abstract}

\section{Introduction}

The plant cell wall is a complex structure that gives strength and shape to the cell, ensures cohesion within tissues and relays signals from the outside environment. The cell wall is a composite consisting of polysaccharides, proteins, phenols and ions. Pectin, a major component of primary cell walls in dicots and nongraminaceous monocots, is a highly diverse polysaccharide and can contain up to 17 different sugar residues (Ridley et al., 2001). Pectins are galacturonic acid (GalA)-containing polysaccharides, and depending on the backbone and side chain composition, they comprise distinct structural classes: homogalacturonan (HGA), rhamnogalacturonan (RGI), rhamnogalacturonan II (RGII) and substituted galacturonan: xylogalacturonan (XGA) and apiogalacturonan (AGA) (Caffall et al., 2009). The complexity of the pectic polysaccharides is further increased by the side chain composition and acetylation and methylation of the backbone. For example, in RGI the side chains consist of either galactan, arabinan or arabinogalactan of different length and branching patterns. The exact structure and composition of pectin differs, not only between species and varieties of a single species (Ross et al., 2010a) but also per cell type and during development (Bush et al., 2001; Robert et al., 2011). The chemical composition and physical-chemical properties of cell walls are determinant of the biological function (Willats et al., 2001).

To study cell wall polymer structure-function relationships, mutant screens have been performed which resulted in the identification and characterization of genes encoding cell wall biosynthetic enzymes (Mouille et al., 2003). A number of murus (mur) loci that determine sugar composition of cell wall polysaccharides were identified (Chen et al., 1998; Reiter et al., 1993, 1997). Most of this work was performed in the model plant Arabidopsis (reviewed by Liepmann et al., 2010).

Other strategies to study structure-function relationship comprise the use of a transgenic approach, by altering gene expression, functional testing in a heterologous system and complementation of (knockout) mutants. For potato, several transgenic lines with a modified pectin/cell wall composition in the tubers are available. These lines have been generated by heterologous expression of different fungal and plant cell wallmodifying enzymes. Fragmentation of RGI backbone in potato was achieved by expressing a rhamnogalacturonan lyase (RGL) enzyme from Aspergillus aculeatus (Oomen et al., 2002). The introduction of RGL resulted in reduction and altered location of the pectic galactan and arabinan side chains and abnormal periderm development of tubers (Oomen et al., 2002). The expression of $A$. aculeatus endo-1,4- $\beta$-D-galactanase (3eGAL, Oxenboll Sorensen et al., 2000) and $\beta$-galactosidase ( $\beta$-GAL) from Cicer arietinum (Martin et al., 2005) led to a reduction in the galactan side chains of $\mathrm{RGI}$. A reduction in galactose content up to $30 \%$ and $50 \%$ was observed, respectively. The reduction of arabinan in RGI was achieved by expressing Golgi membraneanchored endo- $\alpha$-1,5-L-arabinanase (eGARA) from $A$. aculeatus, which led to a $70 \%$ decrease in arabinose content in cell walls (Skjøt et al., 2002). Influencing the availability of nucleo- 
tide-sugar pools necessary for pectin biosynthesis by overexpression of two different potato UDP-Glc 4-epimerases that convert UDP-glucose to UDP-galactose resulted in significant increase in galactose content of potato tuber cell wall (Oomen et al., 2004). The degree of acetyl esterification of HGA and RGI backbones in potato was reduced by introduction of mung bean pectin acetyl esterase (Orfila et al., 2012). The effect of the transgenes on cell wall composition (see Figure 1) is predominantly in the length and amount of neutral side chains of the $R G I$ part of pectin: less galactose in eGAL and $\beta-G A L$ lines, less arabinose in eGARA and in the RGL lines a reduction in both arabinose and galactose. Lines expressing an UGE gene have increased galactose in their cell walls, presumably in galactan chains (Oomen et al., 2004).

Effects of changed cell wall composition on mechanical properties of tissues were described by Ulskov et al. (2005) who measured the effect of removal of the neutral side chains of RGl on the strength needed to induce collapse of the cell wall in potato tubers. These studies were extended to comprise the determination of relaxation spectra for wild-type and transgenic potato tissues (Hansen et al., 2011). Removal of either arabinan or galactan side chains of pectin resulted in tubers that were more brittle. Altered cell wall hydration properties were proposed to contribute to these effects. Modulation of RGI hydration properties is not only brought about by genetic modification, but is biologically relevant, for example, as mucilage is released during seed imbibition (Arsovski et al., 2009 and references therein). Potato tubers expressing the eGAL gene showed no overall visual phenotype but displayed increased pectin solubility by endopolygalacturonase/pectin methyl esterase digestion (Oxenboll Sorensen et al., 2000). Analysis of textural properties of cooked potatoes revealed a relationship between pectin methyl esterase (PME) activity and resistance to fracture (Ross et al., 2010b). Similarly, in tomato fruits, down-regulation of a specific PME isoform influences fruit softening (Phan et al., 2007).

Very little is known about (developing) pollen cell wall composition. One of the few reports was by Majewska-Sawka et al. (2004) who studied pectin epitopes in developing microspores in sugar beet. Recently, overexpression of a poplar pectin acetyl esterase in tobacco plants was described, leading to changes in cell wall composition in several tissues, especially in the degree of acetylation (Gou et al., 2012). Transgenic plants showed reduction in cell elongation in stylar tissues and filaments and reduced male fertility because of abnormal pollen grain development, which led to lowered pollen germination and pollen tube elongation.

In this paper, the phenotypes of potato transgenic lines with one or two pectin-modifying enzymes were analysed. Transgenic lines with modified pectin were crossed. Unexpectedly, some transgenic lines performed very poorly in crossing experiments. When some of the transgenic lines were used as a pollen donor, the transgene was not transmitted to the next generation. The effects of changes in pectin composition and structure on pollen fertility were investigated.

\section{Results}

Most potato lines transformed with pectin-modifying enzymes showed expression of the transgene, but no alterations in morphology

Potato lines transformed with pectin-modifying enzymes (overview in Figure 1) rhamnogalacturonan lyase (RGL, Oomen et al., 2002), endo-1,4- $\beta$-D-galactanase (eGAL, Oxenboll Sorensen et al., 2000), endo- $\alpha-1,5$-L-arabinanase (eGARA, Skjøt et al., 2002), $\beta$-galactosidase ( $\beta$-GAL, Martin et al., 2005), UDP-Glc 4-epimerase (UGE, Oomen et al., 2004) and pectin acetyl esterase (PAE, Orfila et al., 2012) were transferred from tissue culture to the greenhouse and grown in pots until tubers were formed. Adult plants were analysed and, as reported in previous studies, none of the transgenic lines showed a visual phenotype neither on the aerial part of the plant nor on the tubers. The only exception to that were lines expressing the rhamnogalacturonan lyase, which formed small elongated tubers with a wrinkled surface (Oomen et al., 2002). Because the GBSS promoter used to drive expression of the transgene is mainly limited to tubers and pollen, a gross morphological phenotype was not expected.

The expression levels of the transgenes in the tubers were analysed for each of the transgenic lines containing a single pectin-modifying gene, and the results are shown in Figure $2 \mathrm{a}$. In all the transgenic lines, the transgenes were highly expressed. Expression of the RGL transgene was 15- to 20fold higher than that of the reference gene (elongation factor $1-\alpha, E F 1 \alpha$ ). For the endogenous UGE gene, the expression was increased 10- to 25-fold, depending on the transgenic line. The smallest fold change was detected for the $\beta$-galactosidase transgene, 5-fold. The expression of eGAL, eGARA and PAE transgenes
Figure 1 Schematic presentation of activity of pectin-modifying enzymes in the transgenic lines used in this study. The majority of the enzymes have a pectin-degrading function: arabinanase (eGARA), rhamnogalacturonan lyase (RGL), galactanase (eGAL) and $\beta$-galactosidase ( $\beta$-GAL). Pectin acetyl esterase (PAE) reduces the acetylation of the pectic backbone. UDPGlc-4-epimerase (UGE) catalyses the conversion of UDP-glucose to UDP-galactose, which is used as a building block for galactan side chain biosynthesis. $R G I$, rhamnogalacturonan I.

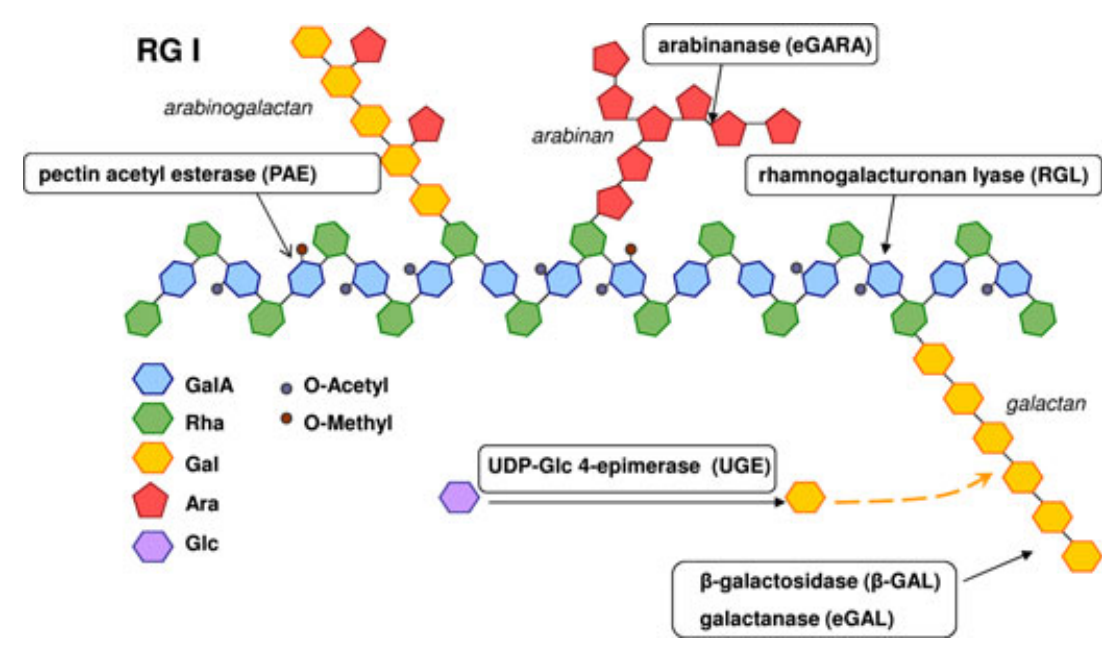




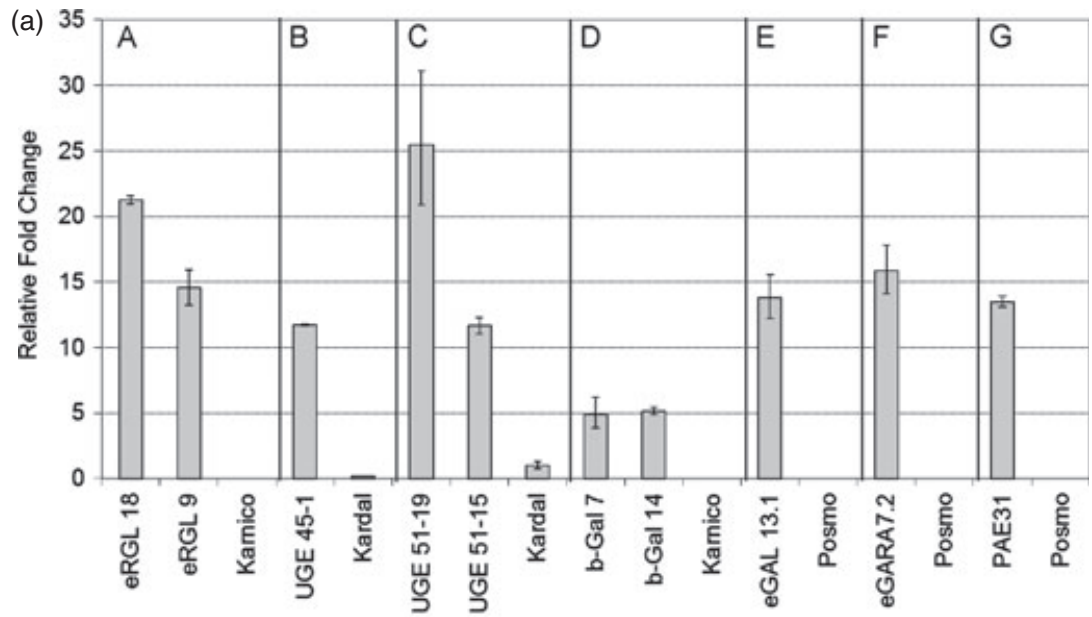

(b)

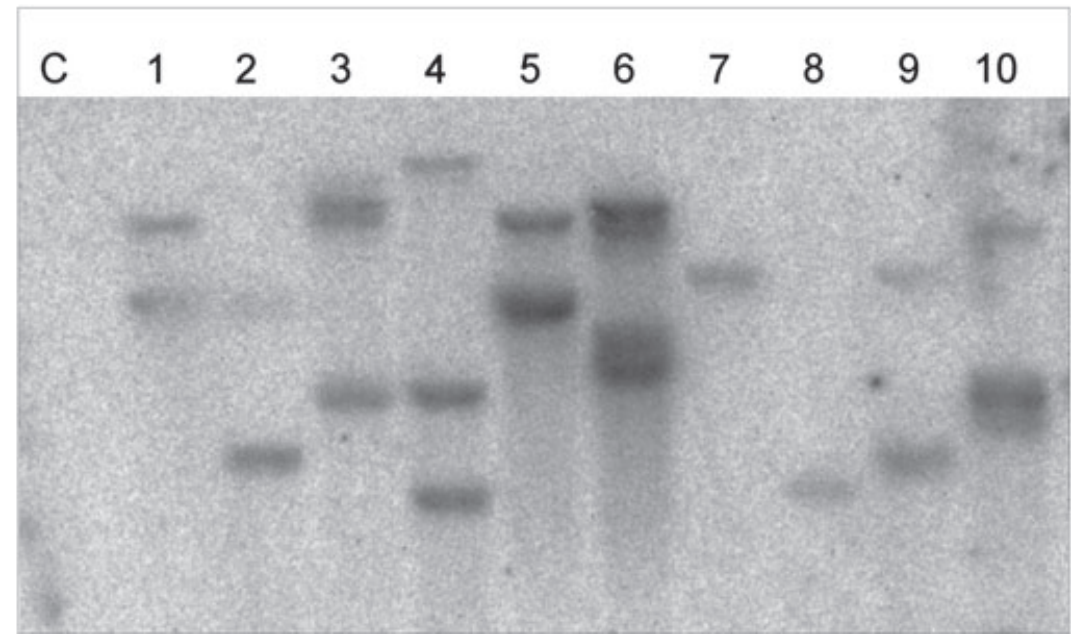

Figure 2 Molecular analysis of the transgenic lines. (a) Relative gene expression of pectinmodifying enzymes in tubers of transgenic potato plants. The values are expressed in fold change relative to the expression of the elongation factor $1-\alpha$ (AB061263). A-rhamnogalacturonan lyase, B-UDP-Glc 4-epimerase 45, C-UDP-Glc 4-epimerase $51, \mathrm{D}-\beta$-galactosidase $\mathrm{E}$ - endo-1, 4- $\beta$-D-galactanase, $F$ - endo- $\alpha-1,5-L$-arabinanase and $\mathrm{G}$ - pectin acetyl esterase. Transgenic lines were compared to their corresponding background variety (Kardal, Karnico or Posmo). (b) Transgene copy numbers. C - untransformed Karnico, Posmo and Kardal; 1 -RGL-9, 2-RGL-18, 3- $\beta$-Gal 7, 4- $\beta$-Gal 14, 5- eGARA 7.2, 6-eGAL 13.1, 7-PAE 31, 8-UGE 45-1, 9-UGE 51-15, 10-UGE 51-19. The probe used for hybridization was specific for part of the NPTIl gene. was increased by 13-, 16- and 13-fold, respectively, compared to EF1 $\alpha$.

\section{Potato lines expressing pectin-modifying enzymes have altered monosaccharide composition in the tuber cell wall}

Monosaccharide composition of cell wall material was screened by HPAEC for the main pectic monosaccharides: galactose, galacturonic acid, arabinose and rhamnose. The analysis revealed that the pectin composition of the tuber cell walls was modified (Figure 3) in accordance with previous reports. Increase in galacturonic acid content and decrease in galactose and arabinose contents in comparison with WT cultivar Karnico were detected for RGL line 18, as expected. For $\beta$-galactosidaseexpressing lines, the galactose content was found to be reduced both for $\beta-G a l-14$ and for $\beta-G a l-7$ lines compared to Karnico. In lines UGE41-1 and UGE51-19, the galactose content was increased compared to WT variety Kardal. The eGARA line expressing an arabinanase enzyme had reduced arabinose content and the eGAL line had reduced galactose content compared to WT variety Posmo. Lines expressing both eGAL and eGARA (eGAL+eGARA)-10 and -13, respectively, had both reduced arabinose and galactose contents in the cell wall. Increased galactose in the cell wall was observed in lines expressing an UGE gene.

\section{Crossing of potato transgenic lines expressing pectin-modifying enzymes}

Crossing of transgenic potato lines was attempted for all possible combinations of transgenic lines with modified pectin composition. Each line was used both as a pollen donor and as a female parent. The number of crossing attempts, percentage of berry formation and number of seeds obtained from each cross are depicted in Table 1. Potato lines expressing the rhamnogalacturonan lyase gene had less flowers. Due to the reduced number of flowers, crossing with RGL line 9 was performed only 20 times with this line being a pollen donor and 16 times with this line as the female parent. No berries were formed. Two independently transformed lines with the double construct eGAL+eGARA which showed both reduced galactose and arabinose contents of tuber cell walls were put in the greenhouse and showed reduced flower production. Berries were formed and harvested, although percentages of crosses that produced berries and numbers of seeds per berry highly varied between crosses as is shown in Table 1.

\section{Copy number of transgenes}

The number of transgene insertions was analysed for all lines using a probe for the kanamycin resistance gene (Figure $2 \mathrm{~b}$ ) and with gene-specific probes. Southern blot analysis showed that 
Figure 3 Monosaccharide composition of tuber cell wall material. The relative content of rhamnose (rha), arabinose (ara), galactose (gal) and galacturonic acid (galA) was screened in cell walls of transgenic potato tubers.

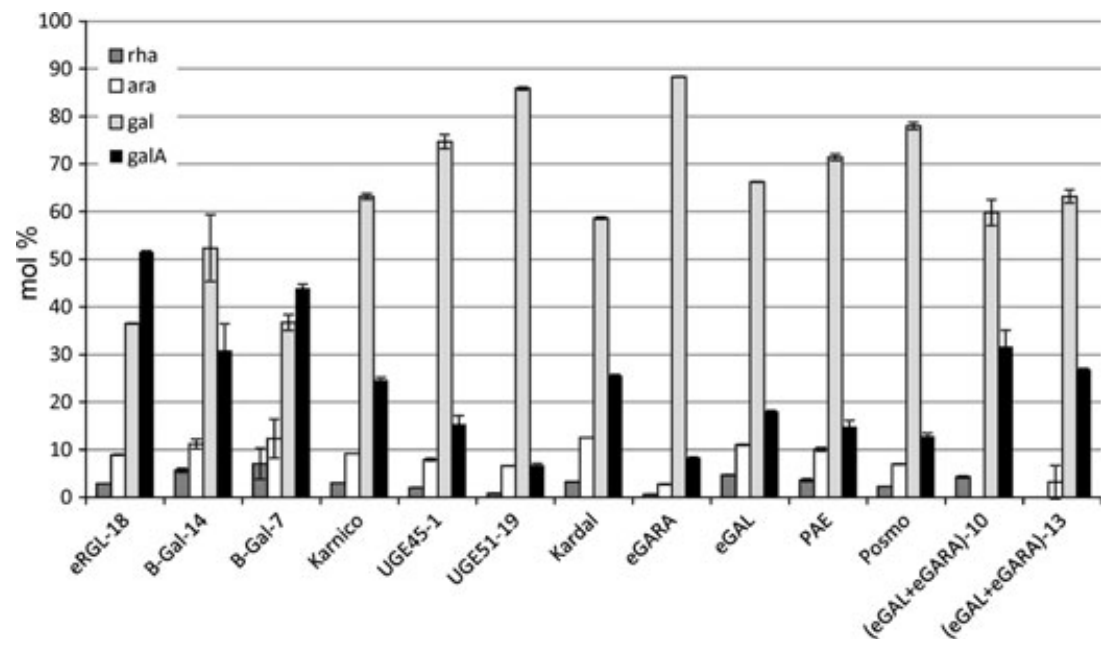

Table 1 Crossing results for potato lines with modified pectin composition

\begin{tabular}{|c|c|c|c|c|c|c|}
\hline \multirow[b]{2}{*}{ Transgenic line } & \multicolumn{3}{|c|}{ Female parent } & \multicolumn{3}{|c|}{ Pollen donor } \\
\hline & $\begin{array}{l}\text { Crossing } \\
\text { attempts }\end{array}$ & $\begin{array}{l}\% \text { Berry } \\
\text { formation }\end{array}$ & $\begin{array}{l}\text { Seed } \\
\text { number }\end{array}$ & $\begin{array}{l}\text { Crossing } \\
\text { attempts }\end{array}$ & $\begin{array}{l}\% \text { Berry } \\
\text { formation }\end{array}$ & $\begin{array}{l}\text { Seed } \\
\text { number }\end{array}$ \\
\hline RGL-9 & 16 & 0 & 0 & 20 & 0 & 0 \\
\hline RGL-18 & 57 & 22 & 875 & 48 & 49 & 1570 \\
\hline UGE45-1 & 122 & 30 & 1140 & 67 & 27 & 610 \\
\hline UGE51-15 & 104 & 31 & 1506 & 49 & 29 & 780 \\
\hline UGE51-19 & 59 & 39 & 785 & 59 & 58 & 3250 \\
\hline$\beta$-Gal-7 & 47 & 8 & 715 & 83 & 56 & 3290 \\
\hline$\beta$-Gal-14 & 46 & 16 & 415 & 76 & 16 & 316 \\
\hline eGAL-13.1 & 69 & 65 & 2890 & 82 & 47 & 2675 \\
\hline eGARA-7.2 & 19 & 71 & 1150 & 64 & 31 & 960 \\
\hline (eGAL+eGARA)-10 & 65 & 43 & 1416 & 25 & 0 & 0 \\
\hline
\end{tabular}

both the UGE45-1 and PAE lines contain a single copy of the transgene. Two copies were detected in lines eGARA and both RGL lines ( 9 and 18). Lines UGE51-19 and eGAL 13.1 and $\beta$-GAL7 contained three copies. The transgene copy numbers were used to predict the expected gene segregation ratio for F1 plants after crossing experiments as listed in Table 2.

\section{Skewed segregation of the transgenes in F1 populations indicates male sterility}

Seed lots obtained in crosses of potato lines with modified pectin were germinated and transferred to soil. For each F1 seedling, the presence of transgenes from the parental lines was tested by $P C R$ on genomic DNA. Potato $(2 n=4 x=48)$ has four copies of a sole genome consisting of 12 chromosomes that are inherited independently (tetrasomic inheritance). T-DNAs carrying transgenes inserted in the genome of tetraploid potato showed a Mendelian inheritance (Zhu et al., 2013). The expected segregation ratio in potato plants with a single transgene copy is $1: 1$, indicating $50 \%$ of the offspring will carry the transgene. Segregation ratios for plants with two or three transgene copies are $3: 1$ and $7: 1$, respectively, resulting in $75 \%$ and $86 \%$ of the offspring carrying at least one copy of the transgene assuming that the transgenes were inserted in the genome independently. For potato lines containing eGAL, $\beta$ -
GAL, UGE and PAE, the transgene was transmitted to the $F 1$ generation and the segregation ratio closely resembled the expected segregation ratio based on the insert copy number (see Table 2). For the rhamnogalacturonan lyase line, the transgene segregation ratio resembled the expected segregation ratio of 3: 1 when RGL line 18 was used as a maternal plant (with 2 inserted T-DNA copies). However when this line was used as a pollen donor, the transgene was detected only in $4 \%$ of the offspring (290 plants tested). A similar effect was observed in the case of potato line containing the eGARA gene. The gene was present in $56 \%$ of the $F 1$ plants when the eGARA line was used as a maternal parent (one copy of the transgene, 111 F1 plants tested); however, the gene was not detected in any of the F1 seedlings when the eGARA line was used as a pollen donor (224 F1 plants tested). The line carrying the double construct eGAL+eGARA could not be used as a pollen donor (no berries/ seeds were formed), but the transgenes could be detected in $80 \%$ of the offspring (176 plants tested, derived from four separate crosses) when this line was used as a mother. These skewed segregation of transgenes indicated a male sterility phenotype for potato lines expressing the endo- $\alpha-1,5$-L-arabinanase, rhamnogalacturonan lyase or the double construct eGAL+eGARA. The pollen of these lines was investigated further. Like the parental lines used in crosses, the F1 offspring 
Table 2 Segregation ratios of transgenes in F1 population

\begin{tabular}{|c|c|c|c|c|c|}
\hline \multirow[b]{2}{*}{$\begin{array}{l}\text { Transgenic } \\
\text { line }\end{array}$} & \multicolumn{2}{|c|}{ Used as female parent } & \multicolumn{3}{|c|}{ Used as pollen donor } \\
\hline & $\begin{array}{l}\text { F1 plants } \\
\text { tested }\end{array}$ & $\begin{array}{l}\text { Segregation } \\
(\%)\end{array}$ & $\begin{array}{l}\text { F1 plants } \\
\text { tested }\end{array}$ & $\begin{array}{l}\text { Segregation } \\
(\%)\end{array}$ & Expected segregation \\
\hline RGL-18 & 252 & 69 & 290 & 4 & 75 \\
\hline$\beta$-Gal-7 & 48 & 92 & 440 & 95 & 86 \\
\hline UGE45-1 & 339 & 48 & 162 & 57 & 50 \\
\hline UGE51-19 & 199 & 94 & 60 & 95 & 86 \\
\hline eGARA-7.2 & 111 & 56 & 224 & 0 & 75 \\
\hline eGAL-13.1 & 82 & 72 & 165 & 75 & 86 \\
\hline eGAL+eGARA-10 & 176 & 79 & No seeds $f$ & & 75 \\
\hline PAE-31 & 376 & 51 & 68 & 36 & 50 \\
\hline
\end{tabular}

showed no gross morphological phenotypes of stems, leaves and flowers.

\section{A decrease in arabinan drastically reduces pollen viability}

Pollen viability was investigated in lines where skewed segregation ratios were detected: RGL, eGARA and eGAL+eGARA transgenic lines, and compared to the respective untransformed potato backgrounds as well as to a line where galactan content was increased (UGE 45-1).

For the RGL lines, cross-sections of anthers from flowers before anthesis were stained with toluidine blue (TB) and compared to the wild-type background (Karnico). The results showed that the majority of the pollen grains in the RGL-18 were not stained with
TB and are devoid of cytoplasm or only stained at the kin pore, indicating that they are not viable. In the control Karnico, most of the pollen grains stained blue (Figure 4a). Similar results were found for anthers of transgenic lines with the eGARA transgene or with the double construct eGAL+eGARA (data not shown). In addition to the TB staining, the viability of pollen grains in the eGARA, eGAL+eGARA and UGE transgenic lines was analysed with modified Alexander's stain (Peterson et al., 2010). Viable or fertile pollen with cytoplasm stain pink, and pollen without cytoplasm stain greenish/blue. The plants were grown in the greenhouse in 2010, and again in 2011, and the results of the staining are presented in Figure $4 \mathrm{~b}$. In the untransformed Karnico, Posmo and Kardal plants, $60-70 \%$ of the pollen is viable. In lines with reduced pectic arabinan (eGARA, eGAL+eG- (a) Control

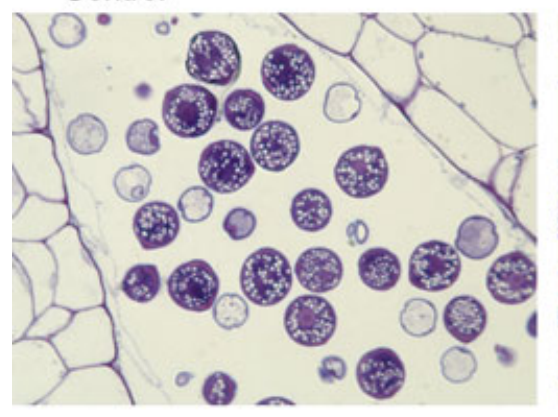

(b)

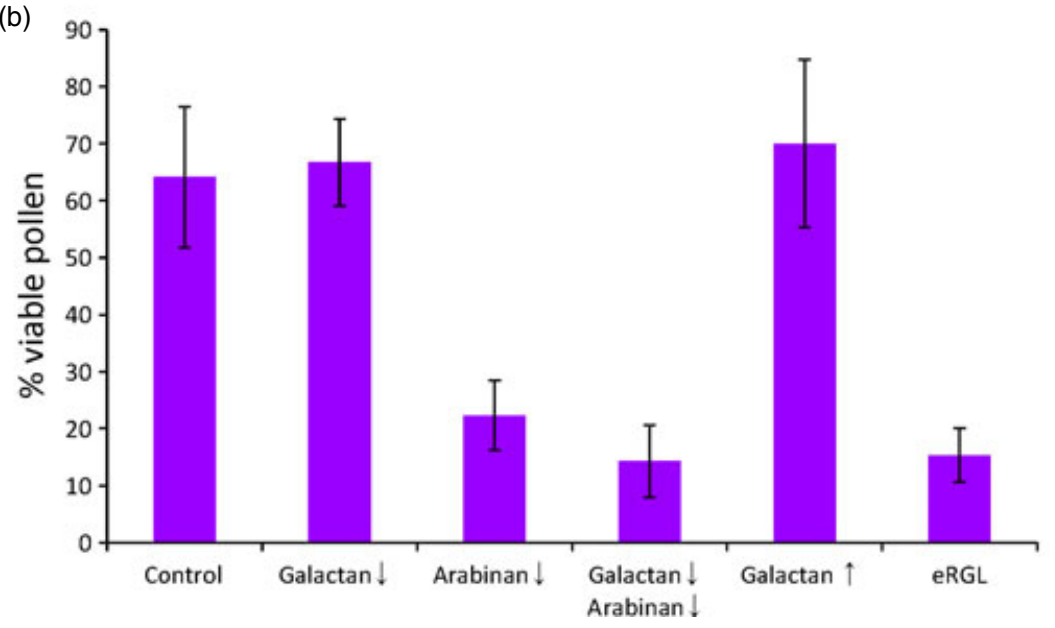

Figure 4 Pollen viability in potato transgenic lines. (a) Light microscopy of cross-section of anthers from flowers just before anthesis, stained with basic dye toluidine blue. On the left, anther from control plant with majority of pollen grains staining intensely blue. On the right, anther from line with $R G L$ transgene with majority of the pollen grains not viable, seen as nonstained grains or grains stained only at the kin pore. Bar: $50 \mu \mathrm{m}$. (b) Pollen viability as percentage of total pollen (average \pm SD). Pollen was collected from open flowers of greenhouse-grown plants (grown in 2010 and 2011) and stained with modified Alexander's solution. Lines with reduced galactan (eGAL-13.1) or increased galactan (line UGE45-1) were not significantly different from control lines. Lines with reduced arabinan (eGARA-7.2) or a combination of decreased arabinan plus decreased galactan both (eGAL+eGARA)-10 and eRGL have significantly reduced fertility compared to the other lines $(P \leq 0.01)$. 
ARA and $R G L)$, viability is reduced to $14-28 \%$. In lines with reduced galactan (eGAL or $\beta$-GAL lines) or increased galactan (with UGE transgene), the pollen viability is not different from untransformed controls.

\section{Pollen reduced viability co-segregates with presence of transgene RGL or eGARA}

Pollen viability was determined for F1 plants resulting from crosses between the transgenic lines mentioned in Table 1. F1 plants that inherited the eGARA transgene from the mother showed reduced pollen viability (Figure S2). Likewise, F1 plants that inherited the RGL transgene from the mother showed reduced pollen viability, whereas F1 plants with other transgenes showed pollen viability similar to untransformed control plants. Differences in pollen viability between the groups were found to be statistically significant for the RGL transgene and for the eGARA transgene.

\section{Pollen grains in RGL and eGARA transgenic lines have a collapsed pollen phenotype}

Flower buds of different sizes, representing different developmental stages, were collected from flowering greenhouse plants (Figure S1). Complete buds or isolated anthers were fixed, embedded and stained with toluidine blue (TB) and DAPI to be able to see structures and determine marker events for development. In the earliest developmental stage examined, the flower bud is about $3 \mathrm{~mm}$ and in the anthers the pollen mother cells
(PMC) are visible as dense blocky cells. Up to this stage, no differences were observed between the transgenic plants and the wild type. In flower buds of around $6 \mathrm{~mm}$, the microspores have just been released and the tapetum starts to degenerate. Closed flowers just prior to anthesis contain mature pollen (data not shown). Pollen in young and mature anthers was examined by cryo-scanning electron microscopy. For plants with transgenes $R G L$ or eGARA, an unusual pollen phenotype was observed. Pollen grains with evaginations of the intine at the kin pore were found as shown in Figure 5. Cytoplasm seems to be bulging out and is barely contained by the pollen cell wall. Cross-sections examined by transmission electron microscope confirmed that the evaginations are filled with cytoplasmic material and that the pollen grains burst at the location of the kin pore. In the untransformed control, potato variety Karnico, sometimes kin pores were slightly elevated in pollen grains as shown in Figure 4, but no formation of large evaginations or pollen bursting at the kin pore was observed. Transmission electron microscopy also revealed that large amount of fibrous material is deposited under the kin pores; however, this texture is less dense in pollen grains of the RGL-18 line compared to pollen from control plants (Figure 5).

\section{Pollen mother cells of transgenic lines have altered pectin composition}

Thick sections $(5 \mu \mathrm{m})$ of developing anthers from young flower buds $(3 \mathrm{~mm}$ ) were examined by light microscopy to localize pectin epitopes in the cell walls of pollen mother cells (PMCs).
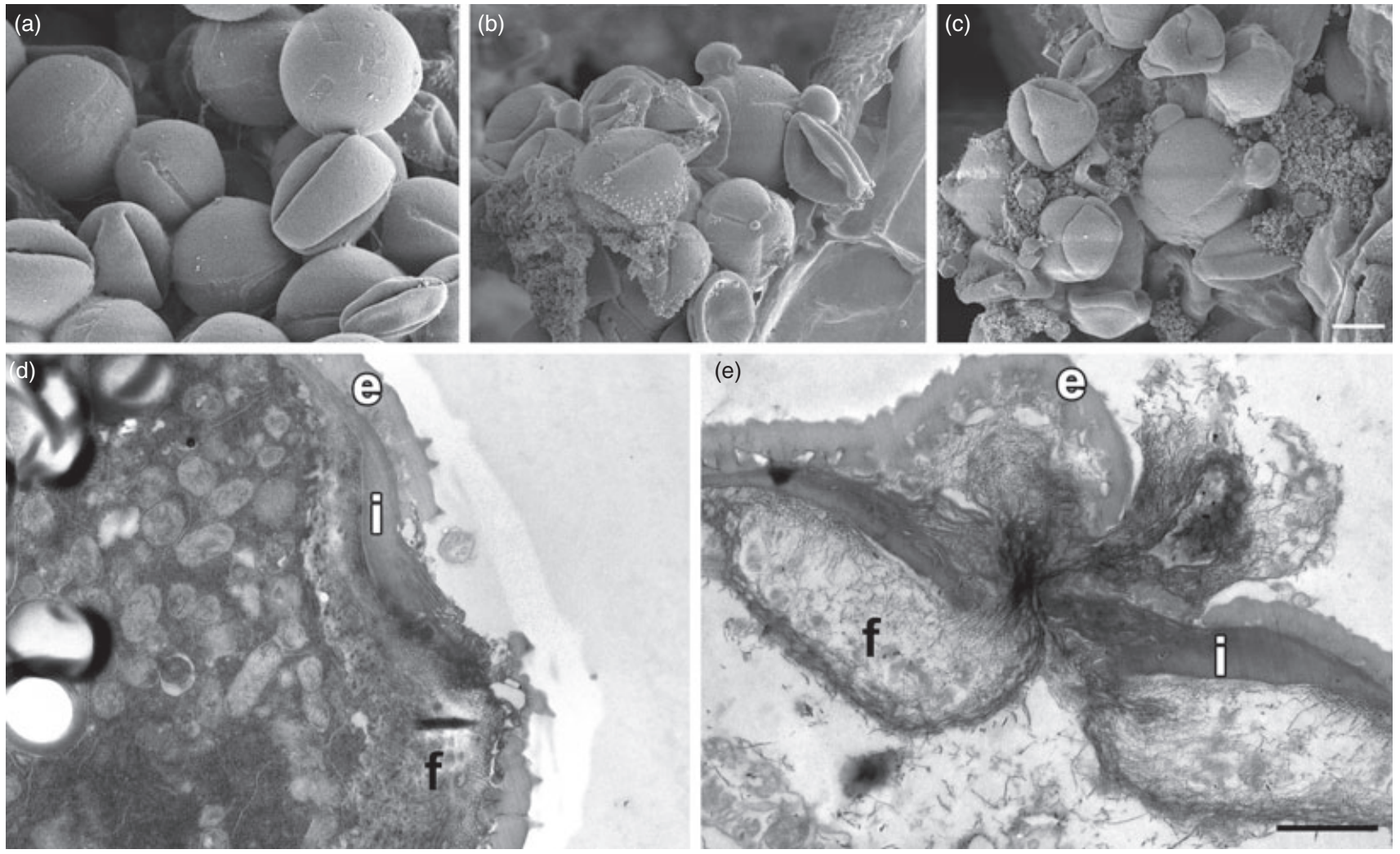

Figure $5(a, b, c)$ Scanning electron microscopy (SEM) of developing pollen in maturing anthers (closed flowers). (a) Control, (b) line eRGL18, (c) line eGARA7.2. Evaginations of intine at the site of the kin pore and collapsed pollen in lines with transgene RGL or eGARA are visible in comparison with the correctly formed pollen grains in the WT control. Bar: $10 \mu \mathrm{m}$. (d, e) Transmission electron microscopy (TEM) of cross-section at position of kin pore in developing pollen in maturing anthers. (d) Control, (e) transgenic line RGL-18 The integrity of the pollen cell wall is breached and cytoplasm is leaking out in RGL pollen. Fibrous material is deposited around the site of the kin pore is less dense in the RGL pollen. I, intine; e, exine; $f$, fibrous material. Bar: $1 \mu$ m. 
Immunolabelling of PMCs in RGL, eGARA and untransformed lines, respectively, Karnico and Posmo, with two different antibodies, one with a galactan (LM5) epitope and the other against arabinan (LM6), revealed alterations in pectin composition (Figures 6 and S3). Both galactan and arabinan epitopes were detected in cell walls of PMCs of control plants. PMCs in anthers of an RGL line did not show galactan or arabinan epitope in the cell walls. In this line, only background labelling of the cytoplasm was observed. The PMCs in anthers of similar developmental stage in the eGARA line showed labelling of cell walls with the galactan epitope, but not with the arabinan epitope (Figures 6 and S3).

\section{Discussion}

This study reports the comparison of multiple potato transgenic lines expressing one or two pectin-modifying enzymes, $R G L$, eGAL, eGARA, $\beta-G A L, U G E$ and PAE. The lines were analysed at different levels, and it was shown that they differ in monosaccharide composition of cell walls and gene expression, but in most cases, no visible morphological phenotype was observed except for the eRGL transgenic lines where the tubers showed clear alterations, they were elongated and more irregular than the wild type (Oomen et al., 2002). These results are in line with previous reports as far as this information was available (Martin et al., 2005 and Oomen et al., 2002, 2004; Orfila et al., 2012; Oxenboll Sorensen et al., 2000; Skjøt et al., 2002). Abnormal phenotypes resulting from the expression of the transgene were expected to occur only in those tissues where the promoter is expressed. The $R G L$, eGARA, eGAL and $\beta-G A L$ transgenes were under the control of the potato GBSS promoter (Visser et al., 1991), which is highly active in stolon, in tubers and in developing pollen (Olmedilla et al., 1991) and to a lesser extent in stems and leaves. The PAE gene was under the control of the patatin B33 Class I promoter, which is strongly active in tubers and can be induced in stem and leaves (Rocha-Sosa et al., 1989) by the application of sugars, and the UGE gene was expressed ubiquitously by the $35 \mathrm{~S}$ promoter (Odell et al., 1985).

Reduction of pectic arabinan, but not galactan, leads to collapse of pollen late during development

All the potato transgenic lines were crossed in all combinations, and analysis of the progeny revealed that some of the transgenes, in particular $R G L$, eGARA and eGARA+eGAL, were underrepresented in the $F 1$ populations. Lines with reduced arabinan content (eGARA, eGAL+eGARA, RGL), but not lines with reduced galactan (eGAL, $\beta-G A L$ ) side chains, show reduced male fertility in crossings and the pollen of these lines have reduced viability. This reduced pollen viability is likely caused by the inserted transgenes because it was found to co-segregate with the presence of the transgenes eGARA and RGL in F1 population resulting from crosses (Figure S2). Microscopic analysis of anthers and pollen of these lines showed that the integrity of the pollen cell wall is breached and results in a collapsed pollen phenotype. The collapsed pollen phenotype is observed late in the development at the binucleate stage, after meiosis and the first mitosis are completed. At this late developmental stage, the pollen dehydrates and matures (Taylor and Hepler, 1997). Galactan, although present in the cell walls during both early and later pollen development (Figures 4 and 5), is apparently not essential for pollen viability because eGAL and $\beta$-GAL plants with less galactan and UGE lines with more galactan have no changed fertility (as seen with crossing and staining for pollen viability). In earlier developmental stages, labelling of the cell wall of the pollen mother cell both with antibodies against galactan and arabinan is observed in flowers of control plants. The line expressing RGL
Control
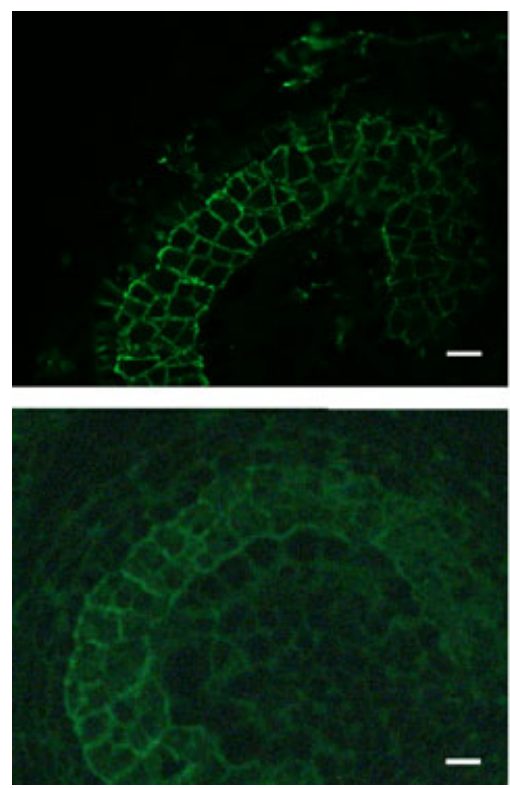

eRGL
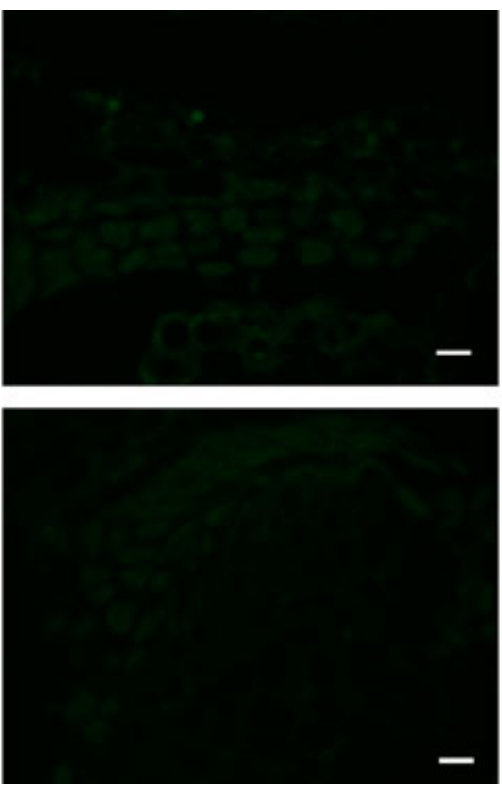

eGARA

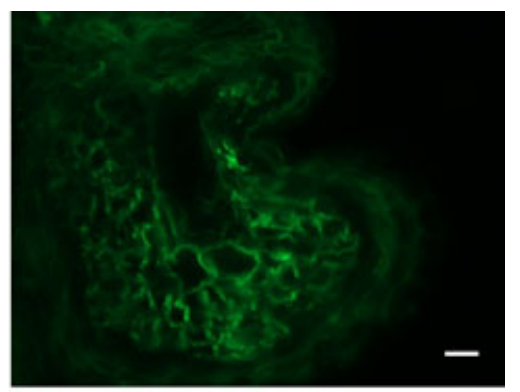

LM 5

galactan

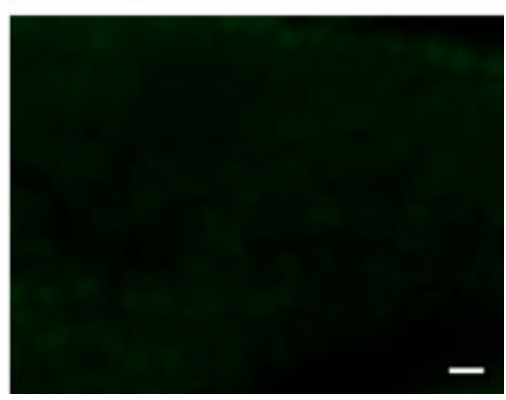

LM 6 arabinan

Figure 6 Immunolabelling of pollen mother cells in developing anthers (flower buds: $3 \mathrm{~mm}$ ). Cell walls of the pollen mother cells (PMC) in the control line show labelling of galactan and arabinan epitopes with LM5 and LM6 antibodies. In the RGL line, the cell walls of the PMC show no labelling at all. The PMCs in the eGARA line show labelling for galactan only. 
does not show the galactan and arabinan epitope in the cell walls of the PMCs, as expected, and the eGARA line only shows labelling of galactan in anthers of similar developmental stage. Apart from the differences in labelling, no major differences were observed in anther morphology and developing pollen at this stage between the different lines, certainly not signs of collapse of the cells. Slight differences in cell morphology that were observed between control (Kardal) and RGL (Karnico) and eGARA (Posmo) anthers could be due to cultivar variation or variation in developmental stages, as well.

\section{Possible mechanism for cell wall failure due to reduction of pectic arabinan side chains}

At anthesis, pollen water content is reduced to $6-60 \%$ of the fresh weight, depending on the species (Pacini et al., 2006). Pollen remains viable and is rehydrated upon landing on a compatible stigma surface. Accumulation of certain molecules, like sucrose, and the structure of the pollen wall itself protect against the mechanical strain during desiccation and rehydration. The intine (consisting of pectin and cellulose) is produced by the microspores, whereas the outer layer, the exine, is deposited on the surface by secretions of the tapetum. Results presented here indicate that removal of pectic arabinan side chains causes failure of the intine, at the site of the kin pore, when the pollen is dehydrating during pollen development, and results in the bursting of the pollen. This explains why the phenotype is only observed in the later stages of pollen development. Pectic side chains function as plasticizers in cell walls that undergo remodelling (Moore et al., 2008). Arabinan and galactan are highly mobile (flexible molecules) polymers compared to the rest of the pectin, and their mobility is influenced by the hydration status of the cell wall, where arabinan is even more mobile than galactan (Ha et al., 2005). The ratio of arabinan to galactan side chains was even suggested to control overall hydration properties of cell walls (Larsen et al., 2011). Upon hydration of dry cell walls, galactan and arabinan are the first to be mobilized (Tang et al., 1999) and the last to lose mobility when dehydrated. The biological importance of arabinan pectin chains in particular was demonstrated by Moore et al. (2006) who showed that cell walls of desiccation-tolerant plants were rich in arabinan side chains of RGI and arabinogalactan proteins and they advanced the hypothesis that the arabinans ensured that the wall would not retrograde during desiccation, but rather be able to reconstitute upon rehydration. Retraction of the pollen wall at the site of the kin pore during dehydration would probably be fatal to pollen function. Another example of the role of arabinan chain function was shown when degradation of arabinan, but not galactan, in guard cells prevents stomatal opening or closing (Jones et al., 2003). The proposed hypotheses infer that arabinan prevents homogalacturonan $(\mathrm{HG})$ domains from forming tight egg-box associations by $\mathrm{Ca}^{2+}$ cross-linking. Future research will focus on elucidating the precise nature of the structure-function relationship of pectin.

Although developing pollen has been carefully described cytologically, there are few reports on cell wall composition of developing pollen although cell wall-remodelling enzymes are amongst the most abundantly expressed during pollen development (Pina et al., 2005). In sugar beet, cell wall composition of developing pollen was studied with monoclonal antibodies against different pectin epitopes. Arabinan was detected in sporogenous cells and meiocytes, but not later than the tetrad stage, and galactan was detected in cell walls of meiocytes, mature (but not young) tetrads, in young and expanding microspores (Majewska-Sawka et al., 2004). In germinating Arabidopsis pollen LM6, detectable arabinan is found evenly distributed over the pollen grain and over the entire length of the pollen tube (Dardelle et al., 2010). Interestingly, the Arabidopsis mutant arad1 (Harholt et al., 2006) with reduced arabinose content in the cell walls of leaves and stems and a T-DNA insertion in a putative glycosyltransferase gene At2 g35100 is not male sterile (data not shown). This gene is very highly expressed in flowers and developing pollen (AtGenExpress). However, a close homologue of this gene (At5 g44930) is also expressed in flower tissues and may be able to compensate for the lack of arad1 function. The importance of the relationship between arabinose metabolism and pollen fertility was very recently demonstrated by Udea et al., 2013, who showed in a forward genetic approach that disruption of an arabinokinase-like-encoding gene, possibly involved in the general arabinose salvage pathway, was responsible for the so-called collapsed abnormal pollen phenotype in rice. Our results, obtained by reverse genetics, point specifically towards the arabinose polymers attached to pectin in the cell wall to be essential for cell wall integrity during pollen development.

\section{Prospects}

Although the tailoring of pectin structure in higher plants is very attractive and far-reaching, it is clear that changes in pectin structure will affect cell wall properties, and can have consequences for essential processes in the plant. In spite of the fact that plants with altered arabinan and/or galactan have a strong reduction in pollen viability, these plants can still be used as female parents, and as they do not have a penalty for yield, they can potentially be used in potato breeding programmes. The fact that these plants show male sterility could be considered to be an advantage, as it can be used as a tool for breeding companies to protect their new varieties. Application of male sterile potato plants would be advantageous in F1 hybrid potato breeding, a strategy that was only recently shown by Lindhout et al., 2011 to be feasible in potato.

\section{Experimental procedures}

\section{Cloning of the double construct eGAL+eGARA}

To express the eGAL and eGARA genes simultaneously and in equimolar amounts, a double construct was build based on the construct described by Øbro et al. (2009) incorporating the 2A sequence into a fusion protein of eGAL and eGARA. An intermediate construct was first prepared to attach a terminator to the coding sequence. The region spanning the coding sequence of the two genes was amplified by primers with added Clal restriction sites using high-fidelity Pfu DNA polymerase and ligated into the Clal site of pRT4 plasmid (pBlue Script plasmid containing t35S terminator) to obtain plasmid PRT4_SOE. The orientation of the fusion protein in the plasmid was checked by restriction analysis and PCR. Two independent clones were sequenced to confirm the fidelity of amplification with Pfu polymerase. The StARA-2A-GAL fragment with the t35S terminator was then excised and cloned into Kpnl site of pBIN_20 (Hennegan and Danna, 1998) that contains the potato granule-bound starch synthase (GBSS) promoter (Visser et al., 1991). The orientation of the insert was confirmed by restriction enzyme analysis and PCR analysis, and the construct was sequenced. The final pGBSS-StARA-2A-GAL-t35S construct in pBIN20 was named pBIN20_SOE and was transferred to 
Agrobacterium tumefaciens strain LBA4404 for plant transformation.

\section{Transformation of potato cultivars}

Transformation of constructs was carried out as described by Visser (1991). Potato cultivars Posmo and Kardal $(2 n=4 x=48)$ were used for transformation experiments. Potato stem segments were co-cultivated for 3 days with $A$. tumefaciens carrying plasmid pBIN20_SOE. After 4-8 weeks, regenerating shoots were collected and cultured on MS (Murashige and Skoog, 1962) medium including 3\% sucrose supplied with $50 \mathrm{mg} / \mathrm{L}$ kanamycin.

\section{Plant material and crossing of potato pectin lines}

Transgenic potato lines expressing pectin-modifying enzymes were available from previous research. The genes that were introduced into potato encode rhamnogalacturonan lyase (RGL lines 9 and 18) (Oomen et al., 2002), endo-1,4- $\beta$-D-galactanase (eGAL, line 13.1) (Oxenboll Sorensen et al., 2000), endo- $\alpha-1,5-L-$ arabinanase (eGARA, line 7.2) (Skjøt et al., 2002), $\beta$-galactosidase ( $\beta$-GAL, lines 7 and 14) (Martin et al., 2005), UDP-Glc 4-epimerase (UGE lines 45-1, 51-15 and 51-19) (Oomen et al., 2004) and pectin acetyl esterase (PAE, line 31) (Orfila et al., 2012). An overview of the (potential) pectin target sites for each of these enzymes is shown in Figure 1. The genes were expressed under the control of the potato GBSS promoter (Visser et al., 1991) except for the UGE gene, which was under the control of the 35 S promoter (Odell et al., 1985), and the PAE transgene, which was driven by the potato patatin promoter (Rocha-Sosa et al., 1989). Five plants of each genotype were transferred from tissue culture to the crossing greenhouse where flowering was stimulated by the removal of side shoots and tubers. The crossing experiments were performed for all possible combinations of transgenes, and each line served as pollen donor as well as the female parent. The flowers were emasculated before anthesis, 2 days prior to pollination. At least 16 independent pollinations on five different days were performed for each crossing combination. Ripe berries were stored at $4{ }^{\circ} \mathrm{C}$ until softening and seeds were collected and air-dried. To break dormancy, F1 seeds were treated with $0.2 \%$ solution of gibberellin (Berelex GA3, Syngenta, Bergen op Zoom, the Netherlands) and sprouted on wet filter paper. After sprouting, seedlings were transferred to the greenhouse and planted in soil.

\section{Determination of insert copy number in potato pectin lines by Southern blotting}

Genomic DNA of greenhouse-grown potato plants was isolated from 0.3 to $0.5 \mathrm{~g}$ of leaves, according to Roger and Bendich (1988). DNA $(10 \mu \mathrm{g})$ was digested with Hind III and separated on $0.8 \%$ agarose gel and subsequently vacuumblotted (Pharmacia) onto Amersham Hybond $\mathrm{N}+$ membranes (GE healthcare) in 10x SSC. Fragments for probe synthesis were obtained by PCR using gene-specific primers listed in Table S1. A probe directed at the NPTIl gene was obtained by PCR using primers NPTII-F-TCGGCTATGACTGGGCACAACAGA and NPTII-R-AAGAAGGC GATAGAAGGCGATGCG. Probes were purified from agarose gel by MinElute gel purification kit (Qiagen) and radioactively labelled with the Rediprime ॥ DNA labeling system (GE healthcare). Hybridizations were performed in glass bottles using a Hybaid hybridization oven, at $65{ }^{\circ} \mathrm{C}$ for $16-18 \mathrm{~h}$. The blots were rinsed at a stringency of $2 x$ SSC, $1 \%$ SDS at $65^{\circ} \mathrm{C}$.

\section{Monosaccharide composition analysis of potato tuber cell wall}

Several tubers of each transgenic line were diced and pooled into one sample. One gram of tuber tissue was freeze-dried and ground to fine powder. The cell wall material (CWM) was extracted as described by Oomen et al. (2003). 3-5 mg of CWM was acid-hydrolysed, dried and dissolved in demineralized water. The monosaccharides were analysed by using highperformance anion-exchange chromatography (HPAEC; Dionex, Sunnyvale, CA) equipped with the $(2 \times 250 \mathrm{~mm})$ CarboPac PA 1 column (Dionex) and postcolumn (Dionex) addition for PAD detection as described by de Ruiter et al. (1992). Millipore water, $0.1 \mathrm{~m} \mathrm{NaOH}$ and $1 \mathrm{~m} \mathrm{NaOAc}$ in $0.1 \mathrm{~m} \mathrm{NaOH}$ were used as eluent, and $0.2 \mathrm{M} \mathrm{NaOH}$ was added to postcolumn for allowance of the PAD detection. A gradient was applied using a flow of $1.0 \mathrm{~mL} / \mathrm{min}$ at $28{ }^{\circ} \mathrm{C}$, of $\mathrm{NaOH}$ of $0-100 \mathrm{~mm}$ and simultaneously of $\mathrm{NaOAc}$ of $0-400 \mathrm{~mm}$. After each run, the column was washed with $1 \mathrm{~m}$ of $\mathrm{NaOAc}$ and $0.1 \mathrm{~m} \mathrm{NaOH}$ for 5 min each and equilibrated with $\mathrm{H}_{2} \mathrm{O}$.

\section{Gene expression analysis}

Total RNA was extracted from potato tubers using a Trizol extraction followed by an additional clean-up step using RNeasy Mini Kit column (Qiagen, Valencia, CA). One microgram of total RNA was treated with DNasel and was reverse-transcribed using iscript cDNA synthesis kit (Bio-Rad, Hercules, CA). For all amplicons, real-time PCR conditions were as follows: initial denaturation at $95^{\circ} \mathrm{C}$ for $3 \mathrm{~min}$; 45 cycles of denaturation at $95{ }^{\circ} \mathrm{C}$ for $15 \mathrm{~s}$, annealing at $60^{\circ} \mathrm{C}$ for $60 \mathrm{~s}$ and extension at $65^{\circ} \mathrm{C}$ for $60 \mathrm{~s}$; followed by melting curve analysis in the temperature range between 65 and $95{ }^{\circ} \mathrm{C}$ at $3{ }^{\circ} \mathrm{C} / \mathrm{s}$. Reactions were run on MyiQ real-time PCR instrument (Bio-Rad) using 1x IQ Sybergreen Supermix (Bio-Rad) and $300 \mathrm{~mm}$ reverse and forward primer concentrations in the PCR. Primers used for $Q R T-P C R$ analysis are listed in Table S2.

\section{PCR analysis of F1 plants}

For PCR screening of F1 seedlings, leaf discs of $1 \mathrm{~cm}^{2}$ were collected from each seedling and ground in $20 \mu \mathrm{L} 0.5 \mathrm{M} \mathrm{NaOH}$ using Tissue striker KS-TSC 100 (Kisan Biotech, Seoul, Korea). The mixture was neutralized by the addition of $20 \mu \mathrm{L}$ of $100 \mathrm{~mm}$ Tris, diluted 40 times in $100 \mathrm{~mm}$ Tris, and $2 \mu \mathrm{L}$ was used immediately for PCR screening. Primers used for PCR are listed in Table $\mathbf{S 1 .}$

\section{Pollen viability staining}

Flowers and anthers were collected and immediately fixed in Carnoy's solution (ethanol: chloroform: acetic acid in a ratio of $6: 3:$ 1) and kept at $4{ }^{\circ} \mathrm{C}$ until samples were examined. Samples were mounted on glass slides and stained with a simplified version of Alexander's stain (Peterson et al., 2010) to discriminate between aborted and nonaborted pollen grains. Viable pollen grains coloured pink, while infertile pollen grains were blue/green corresponding to the cellulose fraction.

\section{Light microscopy and transmission electron microscopy}

To determine anther and pollen developmental stages, developing anthers of flowers of different sizes (Figure S1) were fixed in $4 \%$ paraformaldehyde, $0.25 \%$ glutaraldehyde, in $100 \mathrm{~mm}$ phosphate buffer $\mathrm{pH}$ 7.3, washed and dehydrated through ethanol series and embedded in Technovit 7100, according to 
the manufacturer's recommendation (HeraeusKulzer GmbH, Hanau, Frankfurt, Germany). One- to five-micrometre-thick slices were stained with DAPI and toluidine blue. For transmission electron microscopy (TEM) visualization, anthers were fixed in $2 \%$ glutaraldehyde in $0.1 \mathrm{~m}$ phosphate buffer at $\mathrm{pH} 7.2$ for $2 \mathrm{~h}$ at room temperature, followed by post-fixation in $1 \%(\mathrm{w} / \mathrm{v})$ osmium tetroxide in water. After dehydration in ethanol and propylene oxide, tissues were embedded in Spurr resin. For light microscopy, sections of $1 \mu \mathrm{m}$ were stained by $0.1 \%$ toluidine blue in $1 \%$ disodium tetraborate. For transmission electron microscopy, thin sections were poststained with uranyl acetate and lead citrate according to the standard procedures (described by Verhoeven et al., (2005)) and viewed with a JEOL JEM 100CX II.

\section{Cryo-scanning electron microscopy}

Anthers were glued onto a stub with colloidal carbon adhesive and frozen in liquid nitrogen (as described by Verhoeven et al., 2005). The samples were placed in a transfer holder under vacuum at liquid nitrogen temperature to the cold stage at $-95{ }^{\circ} \mathrm{C}$ into a cryo-preparation chamber CT $1500 \mathrm{HF}$ (Oxford Instruments; High Wycomb, Abingdon, UK). The specimens were sputter-coated with $5 \mathrm{~nm}$ platinum. The specimens were conveyed under high vacuum to the cold stage of a scanning electron microscope equipped with a cold-field emission electron gun (JSM 6300F; Jeol, Tokyo), analysed and recorded at $-180^{\circ} \mathrm{C}$ using a 5-kV accelerating voltage.

\section{Immunolabelling and light microscopy}

Complete flower buds or anthers were collected and fixed overnight at $4{ }^{\circ} \mathrm{C}$ in $4 \%$ paraformaldehyde, $0.25 \%$ glutaraldehyde in phosphate buffer (100 mm, pH 7.3) and dehydrated through an ethanol series to which $10 \mathrm{~mm}$ of dithiothreitol (DTT) was added. The tissue sections were infiltrated with BMM (butyl methacrylate, methyl methacrylate, benzoin ethylether $(0.5 \% \mathrm{w} / \mathrm{v})$, and after polymerization, 5 - $\mu \mathrm{m}$-thick tissue slices were cut and mounted on polylysine-coated glass slides. Sections were stained with toluidine blue for anther and pollen morphology. Immunolabelling was performed using monoclonal antibodies raised against galactan (LM5) and arabinan (LM6) (Jones et al., 1997; Willats et al., 1998), diluted 5-50 times in $0.1 \mathrm{M}$ phosphate-buffered saline (PBS)/1\% BSA. After washing in $0.1 \mathrm{M}$ PBS, the tissue sections were incubated with secondary antibody (Alexa 488 goat anti-rat IgG, 200 times diluted) in PBS $/ 0.1 \%$ acetylated BSA for $2 \mathrm{~h}$ at $37{ }^{\circ} \mathrm{C}$ in the dark. From this point on, the slides were kept in the dark. Excess antibody was removed by washing twice in PBS in the dark followed by two times washing in PBS including $1 \mu \mathrm{g} / \mathrm{mL}$ Hoechst (for visualizing nuclei). A single drop of antifading citifluor/glycerol was added and a glass coverslip placed on the top. Samples were viewed with a Nikon eclipse 80i microscope (Melville, NY). Control reactions were done leaving out the primary antibody.

\section{Acknowledgements}

Paul Knox is appreciated for the LM5 and LM6 monoclonal antibodies. Dirk-Jan Huigen is kindly acknowledged for help with potato crossings. We thank Marjan Bergervoet for help with potato transformation and Luc Suurs and Rene Verhoef for help with monosaccharide analysis.

\section{References}

Arsovski, A.A., Popma, T.M., Haughn, G.W., Carpita, N.C., McCann, M.C. and Western, T.L. (2009) AtBXL1 encodes a bifunctional beta-D-Xylosidase/ alpha-L-Arabinofuranosidase required for pectic arabinan modification in arabidopsis mucilage secretory cells. Plant Physiol. 150, 1219-1234.

Bush, M.S., Marry, M., Huxham, I.M., Jarvis, M.C. and McCann, M.C. (2001) Developmental regulation of pectic epitopes during potato tuberisation. Planta, 213, 69-880.

Caffall, K.H., Pattathil, S., Phillips, S.E., Hahn, M.G. and Mohnen, D. (2009) Arabidopsis thaliana T-DNA mutants implicate GAUT genes in the biosynthesis of pectin and xylan in cell walls and seed testa. Mol. Plant, 2, 1000-1014.

Chen, L., Carpita, N.C., Reiter, W.D., Wilson, R.H., Jeffries, C. and McCann, M.C. (1998) A rapid method to screen for cell-wall mutants using discriminant analysis of Fourier transform infrared spectra. Plant J. 16, 385-392.

Dardelle, F., Lehner, A., Ramdani, Y., Bardor, M., Lerouge, P., Driouich, A. and Mollet, J.C. (2010) Biochemical and immunocytological characterizations of Arabidopsis pollen tube cell wall. Plant Physiol. 153, 1563-1576.

Gou, J.Y., Miller, L.M., Hou, G., Yu, X.H., Chen, X.Y. and Liu, C.J. (2012) Acetylesterase-mediated deacetylation of pectin impairs cell elongation, pollen germination, and plant reproduction. Plant Cell, 24, 50-65.

Ha, M.A., Vietor, R.J., Jardine, G.D., Apperley, D.C. and Jarvis, M.C. (2005) Conformation and mobility of the arabinan and galactan side-chains of pectin. Phytochemistry, 66, 1817-1824.

Hansen, S.L., Ray, P.M., Karlsson, A.O., Jørgensen, B., Borkhardt, B., Petersen, B.L. and Ulvskov, P. (2011) Mechanical properties of plant cell walls probed by relaxation spectra. Plant Physiol. 155, 246-258.

Harholt, J., Kruger Jensen, J., Oxenboll Sorensen, S., Orfila, C., Pauly, M. and Scheller, H.V. (2006) Arabinan deficient 1 is a putative arabinosyltransferase involved in biosynthesis of pectic arabinan in Arabidopsis. Plant Physiol. 140, 49-58.

Hennegan, K.P. and Danna, K.J. (1998) pBIN20: an improved binary vector for agrobacterium-mediated transformation. Plant Mol. Biol. Rep. 16, 129-131.

Jones, L., Seymour, G.B. and Knox, J.P. (1997) Localization of pectic galactan in tomato cell walls using a monoclonal antibody specific to $(1,-4)$ - $\beta$-D-galactan. Plant Physiol. 113, 1405-1412.

Jones, L., Milne, J.L., Ashford, D. and McQueen-Mason, S.J. (2003) Cell wall arabinan is essential for guard cell function. Proc. Natl Acad. Sci. USA, 100, 11783-11788.

Larsen, F.H., Byg, I., Damager, I., Diaz, J., Engelsen, S.B. and Ulvskov, P. (2011) Residue specific hydration of primary cell wall potato pectin identified by solid-state $13 \mathrm{C}$ single pulse MAS and CP/MAS NMR spectroscopy. Biomacromolecules, 12, 1844-1850.

Liepmann, A.H., Wigthman, R., Geshi, N., Turner, S.R. and Scheller, H.V. (2010) Arabidopsis-a powerful model system for plant cell wall research. Plant J. 61, 1107-1121.

Lindhout, P., Meijer, D., Schotte, T., Hutten, R.C.B., Visser, R.G.F. and van Eck, H.J. (2011) Towards F1 hybrid seed potato breeding. Potato Res. 54, 301312.

Majewska-Sawka, A., Munster, A. and Wisniewska, E. (2004) Temporal and spatial distribution of pectin epitopes in differentiating anthers and microspores of fertile and sterile sugar beet. Plant Cell Physiol. 45, 560-572.

Martin, I., Dopico, B., Munoz, F.J., Esteban, R., Oomen, R.J., Driouich, A., Vincken, J.P., Visser, R. and Labrador, E. (2005) In vivo expression of a Cicer arietinum beta-galactosidase in potato tubers leads to a reduction of the galactan side-chains in cell wall pectin. Plant Cell Physiol. 46, 1613-1622.

Moore, J.P., Nguema-Ona, E., Chevalier, L., Lindsey, G.G., Brandt, W.F., Lerouge, P., Farrant, J.M. and Driouich, A. (2006) Response of the leaf cell wall to desiccation in the resurrection plant Myrothamnus flabellifolius. Plant Physiol. 141, 651-662.

Moore, J.P., Farrant, J.M. and Driouich, A. (2008) A role for pectin-associated arabinans in maintaining the flexibility of the plant cell wall during water deficit stress. Plant Signal. Behav. 3, 102-104.

Mouille, G., Robin, S., Lecomte, M., Pagant, S. and Höfte, H. (2003) Classification and identification of Arabidopsis cell wall mutants using Fourier-Transform InfraRed (FT-IR) microspectroscopy. Plant J. 35, 393-404. 
Murashige, T. and Skoog, F. (1962) A revised medium for rapid growth and bioassays with tobacco tissue cultures. Physiol. Plant. 15, 473-497.

Nicot, N., Hausman, J.F., Hoffmann, L. and Evers, D. (2005) Housekeeping gene selection for real-time RT-PCR normalization in potato during biotic and abiotic stress. J. Exp. Bot. 56, 2907-2917.

Øbro, J., Borkhardt, B., Harholt, J., Skjøt, M., Willats, W.G.T. and Ulvskov, P. (2009) Simultaneous in vivo truncation of pectic side chains. Transgenic Res. 18, 961-969

Odell, J.T., Nagy, F. and Chua, N.H. (1985) Identification of DNA sequences required for activity of the cauliflower mosaic virus $35 \mathrm{~S}$ promoter. Nature, 313, 810-812.

Olmedilla, A., Schrauwen, J.A.M. and Wullems, G.J. (1991) Visualization of starch-synthase expression by in situ hybridization during pollen development. Planta, 184, 182-186.

Oomen, R.J., Doeswijk-Voragen, C.H., Bush, M.S., Vincken, J.P., Borkhardt, B., van den Broek, L.A., Corsar, J., Ulvskov, P., Voragen, A.G., McCann, M.C. and Visser, R.G. (2002) In muro fragmentation of the rhamnogalacturonan I backbone in potato (Solanum tuberosum L.) results in a reduction and altered location of the galactan and arabinan side-chains and abnormal periderm development. Plant J. 30, 403-413.

Oomen, R.J.F.J., Tzitzikas, E.N., Bakx, E.J., Straatman-Engelen, I., Bush, M.S., McCann, M.C., Schols, H.A., Visser, R.G.F. and Vincken, J.P. (2003) Modulation of the cellulose content of tuber cell walls by antisense expression of different potato (Solanum tuberosum L) CesA clones. Phytochemistry, 65, 535-546.

Oomen, R.J.F.J., Dao-Thi, B., Tzitzikas, E.N., Bakx, E.J., Schols, H.A., Visser, R.G.F. and Vincken, J.P. (2004) Overexpression of two different potato UDP-GIc 4-epimerases can increase the galactose content of potato tuber cell walls. Plant Sci. 166, 1097-1104.

Orfila, C., Dal Degan, F., Jørgensen, B., Scheller, H.V., Ray, P.M. and Ulvskov, P. (2012) Expression of mung bean pectin acetyl esterase in potato tubers: Effect on acetylation of cell wall polymers and tuber mechanical properties. Planta, 236, 185-196.

Oxenboll Sorensen, S., Pauly, M., Bush, M., Skjot, M., McCann, M.C., Borkhardt, B. and Ulvskov, P. (2000) Pectin engineering: modification of potato pectin by in vivo expression of an endo-1,4-beta-D-galactanase. Proc. Natl Acad. Sci. USA, 97, 7639-7644.

Pacini, E., Guarnieri, M. and Nepi, M. (2006) Pollen carbohydrates and water content during development, presentation, and dispersal: a short review. Protoplasma, 228, 73-77.

Peterson, R., Slovin, J.P. and Chen, C. (2010) A simplified method for differential staining of aborted and non-aborted pollen grains. Int. J. Plant Biol. 1, 66-69.

Phan, T.D., Bo, W., West, G., Lycett, G.W. and Tucker, G.A. (2007) Silencing of the major salt-dependant isoform of pectin methyl esterase in tomato alters fruit softening. Plant Physiol. 144, 1960-1967.

Pina, C., Pinto, F., Feijo, J.A. and Decker, J.D. (2005) Gene family analysis of the Arabidopsis pollen transcriptome reveals biological implications for cell growth, division control and gene expression regulation. Plant Physiol. 138, 744-756.

Reiter, W.D., Chapple, C.S. and Sommerville, C.R. (1993) Altered growth and cell walls in a fucose-deficient mutant of Arabidopsis. Science, 261, 1032-1035.

Reiter, W.D., Chapple, C.S. and Sommerville, C.R. (1997) Mutants of Arabidopsis thaliana with altered cell wall polysaccharide composition. Plant J. 12, 335-345.

Ridley, B.L., O'Neill, M.A. and Mohnen, D. (2001) Pectins: structure, biosynthesis, and oligogalacturonide-related signalling. Phytochemistry, 57, 929-967.

Robert, P., Jamme, F., Barron, C., Bouchet, B., Saulnier, L., Dumas, P. and Guillon, F. (2011) Change in wall composition of transfer and aleurone cells during wheat grain development. Planta, 233, 393-406.

Rocha-Sosa, M., Sonnewald, U., Frommer, W., Stratmann, M., Schell, J. and Willmitzer, W. (1989) Both developmental and metabolic signals activate the promoter of a class I patatin gene. EMBO J. 8, 23-29.
Roger, S.O. and Bendich, A.J. (1988) Extraction of DNA from plant tissues. In Plant molecular Biology Manual (Gelvin, S.B. and Schilperoort, R.A. eds), sec A6, pp. 1-10. Dordrecht: Kluwer Academic Publishers.

Ross, H.A., McDougall, G.J., Vincent, J.F., Stewart, D., Verrall, S. and Taylor, M.A. (2010a) Discerning intra-tuber differences in textural properties in cooked Solanum tuberosum group Tuberosum and group Phureja tubers. J. Sci. Food Agric. 90, 1527-1532.

Ross, H.A., Wright, K.M., McDougall, G.J., Roberts, A.G., Chapmann, S.N., Morris, W.L., Hancock, R.D., Stewart, D., Tucker, G.A., James, E.K. and Taylor, M.A. (2010b) Potato tuber pectin structure is influenced by pectin methyl esterase activity and impacts on cooked potato tuber texture. J. Exp. Bot. 62, 371-381.

Ruiter, G.A., Schols, H.A., Voragen, A.G.J. and Rombouts, F.M. (1992) Carbohydrate analysis of water soluble uronic-acid containing polysaccharides with High-Performance-Anion-Exchange-Chromatography using methanolysis combined with TFA hydrolysis is superior to four other methods. Anal. Biochem. 207, 176-185.

Skjøt, M., Pauly, M., Bush, M.S., Borkhardt, B., McCann, M.C. and Ulvskov, P. (2002) Direct interference with rhamnogalacturonan I biosynthesis in Golgi vesicles. Plant Physiol. 129, 95-102.

Tang, H., Belton, P.S., Ng, A. and Ryden, P. (1999) ${ }^{13} \mathrm{C}$ MAS NMR studies of the effects of hydration on the cell walls of potatoes and Chinese water chestnuts. J. Agric. Food Chem. 47, 510-517.

Taylor, L.R. and Hepler, P.K. (1997) Pollen germination and tube growth. Annu. Rev. Plant Physiol. Plant Mol. Biol. 48, 461-491.

Udea, K., Yoshimura, F., Miyao, A. and Hirochika, H. (2013) COLLAPSED ABNORMAL POLLEN gene encoding the arabinokinase-like protein is involved in pollen development in rice. Plant Physiol. 162, 858-871.

Ulskov, P., He, W., Bruce, D., Jorgensen, B., Bruun Qvist, K., Skjot, M., Hepwordh, D., Borkhardt, B. and Oxenboll Sorensen, S. (2005) Biophysical consequences of remodelling the neutral side chains of rhamnogalacturonan I in tubers of transgenic potato. Planta, 220, 609-620.

Verhoeven, T., Feron, R., Wolters-Arts, M., Edqvist, J., Gerats, T., Derksen, J. and Mariani, C. (2005) STIG1 controls exudate secretion in the pistil of petunia and tobacco. Plant Physiol. 138, 153-160.

Visser, R.G.F. (1991) Regeneration and transformation of potato by Agrobacterium tumefaciens. In Plant Tissue Culture Manual (ed. Lindsey, K.) Sec. B5, 1-9. Dordrecht, Boston, London: Kluwer Academic Publishers.

Visser, R.G.F., Stolte, A. and Jacobsen, E. (1991) Expression of a chimaeric granule-bound starch synthase-GUS gene in transgenic potato plants. Plant Mol. Biol. 17, 691-699.

Willats, W.G.T., Marcus, S.E. and Knox, J.P. (1998) Generation of a monoclonal antibody specific to (1,-5)-alpha-L-arabinanan. Carbohydr. Res. 308, 149152

Willats, W.G.T., McCartney, L., Mackie, W. and Knox, J.P. (2001) Pectin: cell biology and prospects for functional analysis. Plant Mol. Biol. 47, 9-27.

Zhu, S., Duwal, A., Su, Q., Vossen, J.H., Visser, R.G.F. and Jacobsen, E. (2013) Vector integration in triple $R$ gene transformants and the clustered inheritance of resistance against potato late blight. Transgenic Res. 22, 315-325.

\section{Supporting information}

Additional Supporting information may be found in the online version of this article:

Figure $\mathbf{S 1}$ Stages of potato flower development.

Figure S2 Pollen viability of T0 transgenics and F1 offspring.

Figure $\mathbf{S} \mathbf{3}$ Immunolabelling of pollen mother cells in developing anthers.

Table S1 Primers used for Southern blot analysis and transgene detection in F1.

Table S2 Primers used for qPCR analysis. 